\section{POSSIBILIDADES DA EDUCAÇÃO FÍSICA NO ENSINO MÉDIO TÉCNICO}

\author{
POSSIBILITIES FOR PHYSICAL EDUCATION IN SECONDARY VOCATIONAL \\ EDUCATION
}

\begin{abstract}
POSIBILIDADES DE LA EDUCACIÓN FÍSICA EN LA ENSEÑANZA SECUNDARIA TÉCNICA
\end{abstract}

\author{
Marlon André da Silva*, Lisandra Oliveira e Silva**, Vicente Molina Neto**
}

\begin{abstract}
Resumo: A educação profissional e tecnológica está em expansão no Brasil, com a atribuição de contribuir para o desenvolvimento material da nação. Porém, é tarefa dos Institutos Federais de Educação (IFes) avançar para além do desenvolvimento material, cabendo-Ihes proporcionar a formação para o pensar, a qual não se restringe à formação de técnicos especializados. A partir desses pressupostos faz-se uma reflexão sobre as possibilidades e os desafios da Educação Física (EF) nos (IFes), partindo-se da seguinte questão orientadora: o fato de os estudantes dos IFes procurarem certificação e qualificação profissionalizante nos Cursos Técnicos Integrados ao Ensino Médio Ihes isenta 0 acesso à cultura corporal de movimento? Metodologicamente, trata-se de um ensaio reflexivo, sem a consideração de dados empíricos. Ao fim, chama-se a atenção para a relação existente entre as possibilidades da EF nos IFes e o embate políticoepistemológico - em nível macro e micro - no contexto da criação dos IFes.
\end{abstract}

\section{Keywords}

Secondary

education.

Vocational

education.

Schools.

Public policies.

Palabras clave

Educación

secundaria.

Educación

profesional.

Instituciones.

Políticas públicas.
Abstract: Professional and technological education is expanding in Brazil in order to contribute to the nation's material development. However, Federal Education Institutes (vocational schools known as IFes) have the task of advancing beyond material development and providing education for thinking, which is not restricted to specialized technical training. Such assumptions lead to reflection about the possibilities and challenges of Physical Education (PE) at IFes guided by the following question: does the fact that IFes students look for certification and professional qualification in Technical Courses Integrated to Secondary Education exempt them from accessing the body culture of movement? From the methodological point of view, this is a reflective essay that does not consider empirical data. Finally, it highlights the relationship between the possibilities for PE at IFes and the political and epistemological debate - at macro and micro levels - within the context of the IFes creation.

Resumen: La educación profesional y tecnológica está en expansión en Brasil, con la atribución de contribuir para el desarrollo material de la nación. Sin embargo es tarea de los Institutos Federales de Educación (IFes) avanzar más allá del desarrollo material, teniendo a su cargo proporcionar la formación para el pensar, la cual no puede estar restricta a la formación de técnicos especializados. A partir de esos supuestos, se reflexiona acerca de las posibilidades y los desafíos de la Educación Física (EF) en los IFes, partiendo de la siguiente cuestión orientadora: ¿el hecho de que los estudiantes de los IFes buscan certificación y calificación profesional en los Cursos Técnicos Integrados a la Enseñanza Secundaria les exime del acceso a la cultura corporal de movimiento? Desde el punto de vista metodológico, se trata de un ensayo reflexivo, sin considerar datos empíricos. Finalmente, se recuerda la relación existente entre las posibilidades de la EF en los IFes y el enfrentamiento político epistemológico - en los niveles macro y micro - en el contexto de la creación de los IFes.
* Instituto Federal Rio Grande do Sul. Campus Canoas. Canoas, RS, Brasil. E-mail: marlon.silva@canoas.ffrs.edu.br

** Universidade Federal do Rio Grande do Sul. Porto Alegre, RS, Brasil. E-mail: lisgba@yahoo.com.br

Recebido em: 19-03-2015 Aprovado em: 16-10-2015 (c) (1) (8) Licence 


\section{CONSIDERAÇÕES INICIAIS 1}

As reflexões apresentadas neste artigo partem da nossa experiência docente em EF, por mais de 20 anos, em escolas públicas e privadas de Educação Básica, na atuação docente em cursos de graduação e pós-graduação nessa área de conhecimento e de pesquisas realizadas nos últimos dez anos com docentes e estudantes nas escolas públicas. Nesse conjunto de experiências, destacamos o fato de um de nós exercer a docência no Instituto Federal Rio Grande do Sul (IFRS) nos últimos quatro anos. Assim, é a partir desse contexto que procuramos alargar nossa compreensão sobre a Educação Física nos diferentes espaços de ensino e aprendizagem, objetivando, por esse viés, contribuir para o reconhecimento crítico das diferentes possibilidades da EF no Ensino Médio Técnico.

Metodologicamente, trata-se de um ensaio reflexivo, sem que se considerem dados empíricos. Entendemos, como princípios de um texto reflexivo, o estranhamento e posterior análise dos fundamentos, dos significados ou das razões de algo. Essa atitude leva em consideração os riscos inerentes a fato de tratar determinado conceito como se o seu significado já estivesse posto, dado para sempre, o que faria com que se parasse de pensar sobre ele. Portanto, a partir desses princípios e da experiência com e no "chão de escola" localizamos, de imediato, como pressuposto deste artigo, nossa posição político-epistemológica que reconhece alternativas e estratégias para os desafios da escola, especificamente da EF, sob a perspectiva dos docentes que nela trabalham diuturnamente.

Em uma referência a Platão (MARCONDES, 2009), poderíamos destacar que as possíveis respostas para os problemas/desafios que enfrentamos em nossa área de conhecimento não dependem de alguém que saiu da caverna (da escola básica) e retorna com a "verdade", ou seja, que vai ensinar como "devem ser" as aulas nas escolas. De qualquer forma, a referência à "Alegoria da Caverna" seria cômica se não fosse trágica, pois partilhamos do entendimento de Fensterseifer (1999), de que essa alegoria inspirou a Pedagogia que conhecemos hoje, e, a partir disso, nosso modo de compreender a política e os espaços para discussão e definição do que é de interesse público e o que isso significa. $E$ isso nos instiga a pensar em educação/formação.

No Brasil, a educação profissional e tecnológica está em expansão, com a atribuição de contribuir com o desenvolvimento material da nação. Porém, é tarefa dos Institutos Federais de Educação avançar para além desse desenvolvimento material, cabendo-Ihes proporcionar uma formação para o pensar. Essa formação, no entanto, só poderá acontecer se não se restringir à capacitação técnica exigida pelos interesses de um mercado de trabalho. Em outros termos, defendemos que "sem uma formação, ao mesmo tempo, de caráter geral (teórico) e específico (prático), reproduziremos modelos dicotômicos, onde a inteligência se concentra na cúpula, submetendo os demais às tarefas que requerem o trabalho manual" (CARVALHO; LACERDA, 2010, p. 311).

Outro pressuposto de partida que apresentamos, neste momento, trata do entendimento de que a EF se justifica e se sustenta no contexto escolar quando integrada ao Projeto Político Pedagógico da escola. As possibilidades desse componente curricular passam pela equalização de um Projeto Pedagógico com o necessário diálogo com os demais componentes curriculares que constituem o currículo escolar. Nesse sentido, a relação que se estabelece entre a Educação, os processos de escolarização e a EF indica como uma pode contribuir com as

1 Uma versão preliminar deste artigo foi apresentada em outubro de 2014 no Seminário Interno de Educação Física do Instituto Federal Sulrio-grandense (IFSul). 
outras (e vice-versa) para que se possa pensar em um projeto de escola exitoso para docentes e estudantes do ensino médio e, por conseguinte, para a sociedade (REIS; MOLINA NETO, 2014). Importa, portanto, pensar, também, sobre questões de fundo, voltadas a compreender 0 Projeto Educativo dos IFes; quais seus principais objetivos educativos; e o que recomendam as Concepções e as Diretrizes dos IFes.

Cientes das dificuldades e dos conflitos imanentes à forma de lidar com o conhecimento a partir dos pressupostos acima mencionados, nos propomos a refletir sobre os desafios e as possibilidades da EF nos IFes partindo da seguinte questão norteadora: o fato de os estudantes dos IFes procurarem certificação e qualificação profissionalizante nos Cursos Técnicos Integrados ao Ensino Médio Ihes isenta o acesso à cultura corporal de movimento?

Este artigo está organizado em quatro seções. Além dessa breve introdução, na seção dois discutimos o contexto dos Institutos Federais de Educação e, na seção três, as relações entre Educação Física, trabalho e mercado. Na seção quatro tratamos das Considerações Transitórias.

\section{CONTEXTUALIZANDO O CENÁRIO: OS INSTITUTOS FEDERAIS DE EDUCAÇÃO}

No momento em que a grande crise financeira internacional dava os primeiros passos, precisamente em 30 de dezembro de 2008, por meio da Lei no 11.892/2008 (BRASIL, 2008) 0 Governo Federal instituiu a Rede Federal de Educação Profissional, Científica e Tecnológica e criou os Institutos Federais de Educação, Ciência e Tecnologia, ou os Institutos Federais. São Instituições de Educação Superior, Básica e Profissional, pluricurriculares, multicampus e descentralizadas, especializadas em Educação Profissional e Tecnológica nas diferentes modalidades de ensino. A constituição dos Institutos Federais e a contribuição da Educação Física para a Educação Profissionalizante têm despertado, de modo incipiente, a atenção de alguns pesquisadores, entre os quais, Silva (2014).

Entretanto, historicamente, é possível afirmar que os Institutos Federais têm raízes antigas: em 1909 foram criadas 19 escolas de Aprendizes e Artífices que, mais tarde, originaram as Escolas Técnicas e os Centros Federais de Educação Tecnológica (CEFETs). Ao longo da história recente do Brasil, em termos de políticas públicas para a educação profissional, é possível identificar que o tratamento dado às Escolas Técnicas Federais, em maior ou menor grau - e não sem resistências - esteve relacionado aos interesses e às concepções de educação das classes que detinham o poder econômico e político no país - especificamente as classes empresariais.

A partir do ano de 2002, após debate com a sociedade civil organizada e com as Unidades da Rede Federal de Educação Profissional, o Governo Federal considerou necessário adotar medidas em relação à Educação Profissional, as quais superassem a perspectiva privatista que dominava o setor há quase duas décadas. Na concepção de Pacheco (2012), a educação profissional precisava estar vinculada aos objetivos sociais de sua pauta histórica e social.

Nesses termos é que vem se constituindo a expansão da Rede Federal de Educação Profissional ${ }^{2}$ que, atualmente, conta com 38 Institutos, aproximadamente 450 campi distribuídos por todo o território brasileiro ${ }^{3}$ (39 no Rio Grande do Sul), além de várias Unidades Avançadas,

2 Expansão somente possível mediante alteração na legislação efetivada em 2005 (Lei no 11.195/2005).

3 Entendemos que, embora os IFes sejam um fenômeno educacional importante de nosso tempo, eles ainda não despertaram a curiosidade acadêmica dos pesquisadores da área da Educação Física, dada a ausência quase total de artigos que versam sobre o tema nas principais revistas da área (considerando-se os extratos A1, A2, B1 e B2 do Qualis Capes). 
atuando em Cursos Técnicos ( $50 \%$ das vagas), em sua maioria na forma integrada com 0 ensino médio, licenciaturas (20\% das vagas) e graduações tecnológicas. Disponibiliza, ainda, cursos de especializações, mestrados profissionais e doutorados voltados, principalmente, para a pesquisa aplicada de inovação tecnológica.

A Lei de criação dos Institutos Federais - Lei no 11.892/2008 - estabelece que o objetivo dessas Instituições Educativas visa a justiça social, equidade, competitividade econômica e geração de novas tecnologias. É de competência dessas Instituições responder - de forma ágil e eficaz - às demandas crescentes por formação profissional, por difusão de conhecimentos científicos e tecnológicos e de suporte aos arranjos produtivos locais e regionais. Ao mesmo tempo, as diretrizes dessas escolas estabelecem o reconhecimento da precedência da formação humana e cidadã, sem a qual a qualificação para o exercício profissional não promove transformações significativas para 0 trabalhador e para o desenvolvimento da sociedade. Assim, as diretrizes preconizam a necessidade de assegurar aos sujeitos as condições de interpretar a sociedade e exercer sua cidadania, na perspectiva de um país fundado na justiça, na equidade e na solidariedade.

Entretanto, não é novidade, para quem trabalha, estuda e pesquisa a realidade educativa, a identificação de certo distanciamento entre o que estabelecem/instituem os documentos oficiais (legislação) e a concretude da ação pedagógica nas escolas. Distância que, em nosso entendimento, precisa ser minimizada. Consideramos que, por meio de uma tradução das intenções, da interpretação dos objetivos citados nas normatizações oficiais e pela leitura e análise do contexto das Instituições, tal distanciamento poderá ser atenuado.

A partir do que foi apresentado até o momento, julgamos pertinentes os seguintes questionamentos: a) 0 que significa para os componentes curriculares da formação básica (propedêuticas) presentes nos currículos dos IFes o fato de estas Instituições se proporem a oferecer uma educação com foco no mundo do trabalho, técnico e tecnológico? b) Como os componentes curriculares dialogam com o Projeto Pedagógico Institucional (PPI) dessas Instituições? d) Como estes componentes garantem seu lugar no currículo escolar? Em síntese, entendemos que esses questionamentos podem ser resumidos na seguinte questão: os componentes curriculares da formação básica, pelo fato de constarem no currículo de um Curso Técnico Profissionalizante, devem propiciar conhecimentos diferentes daqueles tradicionalmente tratados no ensino médio regular?

Nossa interpretação é que, se deixarmos as escolhas referentes à constituição dos cursos técnicos integrados ao nível médio, no interior dos IFes, somente a cargo de pessoas ligadas às áreas técnicas e ao sabor do senso comum (atualmente, muito configurado ideologicamente por uma mídia que compactua com os interesses neoliberais), correremos 0 risco de uma redução da participação dos componentes curriculares relacionados à formação humana (que não tratam de um conhecimento técnico específico) nessas Instituições de ensino. Contudo, não é esse o entendimento exposto nos Projetos Pedagógicos Institucionais (PPIs) e nos Planos Pedagógicos de Cursos (PPCs) dos mais variados Cursos Técnicos Integrados ao Ensino Médio nos IFes. Em sua grande maioria, esses documentos defendem o comprometimento com uma educação integral e interligada à capacitação profissional, o que significa que a opção por uma profissão técnica não libera/dispensa o sujeito de uma formação humana, crítica e reflexiva, dimensões que o caracterizam ser humano.

Ressaltamos que, encharcados pela velocidade das mudanças sociais, que produzem impacto na escola, nossas interpretações não ficam imunes aos mais diferentes interesses 
presentes na escola. Do direcionamento político-pedagógico dado pelas nossas interpretações resultam nossos desafios de ordem didático-metodológica. Isto porque nossos conhecimentos e estratégias metodológicas precisam ser pensados de forma contextualizada, pois a realidade escolar é dinâmica e não existem respostas a priori em nossas ações pedagógicas.

\section{EDUCAÇÃO FÍSICA, TRABALHO E MERCADO}

Em nosso entendimento, e para fins deste artigo, uma das maneiras de enfrentarmos as questões até aqui discutidas, dada a complexidade do contexto em que se inserem, seria analisarmos o que estamos entendendo e quais interpretações estamos fazendo dos principais conceitos aí implicados. De acordo com Apple (2013), há um risco quando paramos de discutir conceitos importantes na Educação, pois estes podem parecer naturalizados - dados e esgotados em suas compreensões. De acordo com esse autor, tratar importantes conceitos referentes à Educação sem o devido aprofundamento teórico pode ser mais uma estratégia utilizada pelas classes dominantes na tentativa de fazer da educação formal um espaço de domínio, objetivando a formação de força de trabalho; seguramente, uma formação voltada ao que é caro aos interesses de pessoas e instituições que, historicamente, vêm obtendo vantagens pessoais ou coletivas (no caso de interesses corporativos) a partir dos padrões ideológicos dominantes.

Entendemos que a complexidade desse contexto refere-se, por exemplo, à quantidade considerável de elementos que dificultam a compreensão das questões macrossociais - a crise do trabalho e do emprego na atualidade; as interferências nos estados e na Educação por parte de grupos com perspectivas políticas conservadoras/neoliberais; e as questões microssociais - 0 enfrentamento, de modo fundamentado e argumentativo pelos docentes de $\mathrm{EF}$, dos problemas do cotidiano escolar, em reuniões pedagógicas e administrativas, ou, ainda, como sobreviver frente às características da intensificação e da precarização do trabalho docente (CONTRERAS DOMINGO, 1997).

A partir do exposto é possível pensar que não é gratuito que a escola se configure em um dos principais lugares de disputa ideológica. Entendemos, como exemplo dessas disputas, as fortes divergências e conflitos que caracterizam as reuniões de docentes, ou reuniões gerais, no interior dos IFes, como "torres de Babel". Na maioria das vezes, são reuniões de acirradas discussões e de intricados consensos, possivelmente acentuadas pelas diferenças significativas de trajetórias e formação profissional dos trabalhadores, além de experiências de vida, filiações pessoais, acadêmicas e políticas, dentre outros elementos.

Nesses embates é possível perceber tanto grupos que compreendem a escola como um problema/desafio na/para a sociedade como os que defendem a escola como local para se pensar alternativas para a atual crise identitária que vivemos. Ambos têm proposições distintas do "que" e do "como" essas mudanças devem ocorrer. É sabido que esses grupos distintos estão fortemente representados na concretude do contexto escolar, logo, a configuração do Instituto não ocorre no vácuo, pois está recheada de resistências e contradições. A perspectiva aqui apresentada é de que existem grupos - representados na concretude do espaço escolar - que defendem que a escola não vai bem e algo precisa ser mudado com urgência, o que incita o pensamento de que a escola passa a ser a origem dos problemas atuais da sociedade. Do mesmo modo, há grupos que defendem que a escola é, sim, um dos lugares importantes a 
serem considerados no enfrentamento desses problemas - por exemplo, as crises identitárias (tanto pessoais quanto institucionais), e entendem a escola como um lugar para se pensar alternativas para esses problemas.

Defendemos, aqui, o entendimento de que não é acertado pensar sobre as possibilidades da EF nos IFes sem considerar os pressupostos citados no parágrafo anterior, sobretudo 0 embate - em nível macro e micro - que configuraram e configuram os próprios Institutos Federais. Em nível macro, é importante estarmos atentos aos embates políticos relacionados à Educação em geral, e à Educação Técnica Profissional em particular, pois muito do que acontece em nível micro é reflexo direto ou indireto das decisões tomadas em nível macro. Para exemplificar, lembramos que foi de um movimento político contrário às concepções privatistas que resultou a Lei 11.195/2005 (BRASIL, 2005), alterando as normativas anteriores que impediam a expansão da Rede Federal de Educação Profissional, Científica e Tecnológica e, por conseguinte, a criação dos IFes. Do mesmo modo, as possibilidades da EF nos IFes, em nível micro, são dependentes da capacidade de participação e argumentação dos docentes nos espaços e âmbitos de discussão no interior de cada campus e, a partir disso, na construção de um coletivo em cada Instituto Federal. Consideramos que, passados seis anos da promulgação da Lei n. 11.892, é possível pensar que cada Instituto - e cada campus - ainda está procurando responder da melhor maneira a pergunta relacionada à sua identidade: afinal, a que vieram os Institutos?

Nesse sentido, não basta dizer que a EF pode desenvolver seus conhecimentos de forma equalizada com os propósitos da Instituição Educativa. É preciso refletir sobre o modo com que a área concretiza sua ação no interior das escolas, o que significa pensar sobre qual a posição ético-política da área de conhecimento na contribuição para a construção da identidade dos IFes.

Assim, se não tivermos posições claras sobre o conhecimento e a ação pedagógica da EF nos Institutos e se não soubermos o que tratar nas aulas de EF dessas escolas, correremos o risco de nos deparar com aqueles que nos dirão o que fazer. $E$ a história recente da $E F$ na escola corrobora esse entendimento, especialmente em relação à subordinação da $E F$ às áreas militar, médica, esportiva, entre outras. 0 que queremos, de fato, dizer é: quem não pensa é pensado pelos outros.

Apresentamos esses argumentos para enfatizar que há o risco de a EF nos IFes, se consentida "ao sabor dos ventos", desenvolver um conjunto de conhecimentos voltado mais ao atendimento das demandas profissionais e à competitividade econômica do que à formação humana e cidadã, ou seja, desenvolver conhecimentos de caráter compensatório.

Em pesquisa realizada em algumas unidades (campi) do IFRS, Silva (2014) chama a atenção para um importante processo de "mutação"4 que está sendo iniciado para a EF nas escolas profissionalizantes. Em relação às escolas analisadas pelo referido autor, a EF estaria mudando suas características devido ao contexto histórico, social e cultural que, atualmente, envolve sua interação com o currículo das Escolas Profissionalizantes.

Nesse processo de mutação identificado por Silva (2014), as características da EF que começam a surgir estão intrinsecamente relacionadas aos interesses e propósitos do currículo dos cursos técnicos. E, diz o autor, a EF migrou do "ambiente" das Escolas Propedêuticas para o "ambiente" das Escolas Profissionalizantes sem alterar suas principais características.

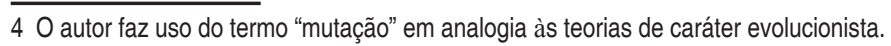


Contudo, os atuais interesses do currículo dos IFes estariam provocando uma mutação na EF (SILVA, 2014). Para esse autor, em alguns casos, o modelo esportivista estaria sendo substituído por um modelo mais teórico e com conteúdos voltados para o cuidado com a saúde do trabalhador em seu ambiente de trabalho (SILVA, 2014).

Concordando com o autor, entendemos que ainda não é possível avaliar em que medida as mudanças que vêm ocorrendo nas características da EF, no interior do currículo das escolas analisadas, podem ser entendidas como mudanças que contribuam ou desafiem a formação humana e cidadã. Outrossim, não é possível ignorar que as mudanças ocorridas aconteceram por interesse do currículo das referidas Escolas Profissionalizantes.

Nosso receio é de que as ações pedagógicas se direcionem prioritariamente ao atendimento dos interesses de um mercado de trabalho ávido por mão de obra barata e qualificada, menosprezando a importância do entendimento dos principais condicionantes sociais, políticos e econômicos que constituem historicamente esse fenômeno (mercado de trabalho), os quais, geralmente, atuam na contramão da formação humana e cidadã.

Em nosso entendimento, exclusivamente atender as demandas do mercado de trabalho é uma ação que está vinculada aos interesses de grupos sociais alinhados à perspectiva da política conservadora e suas ramificações: liberal, neoliberal, neoconservadora, populista autoritária, nova classe média gerencial, dentre outras. Em conjunto, essas forças representam uma "modernização conservadora" de políticas sociais, culturais, econômicas e educacionais, pois conseguem amarrar diferentes tendências sociais e compromissos de diferentes agendas (APPLE; AU; GANDIN, 2011). Entre os interesses e as concepções desses grupos conservadores destacamos a defesa do Estado fraco, estudantes como capital humano e a defesa do mercado livre (o mundo como um supermercado). Na área da Educação, esses interesses se manifestam em ligações mais íntimas/próximas entre escolas e empresas, como trataremos a seguir.

De acordo com Hill (2003), o denominado "modelo de mercado livre" não é um verdadeiro mercado livre. Assim, atualmente, argumentar a favor do "mercado livre", em qualquer âmbito da sociedade, torna-se uma ilusão: o "modelo de mercado" que temos na atualidade é um sistema que beneficia "o mercado corporativo global". E este é um sistema em que as regras desse mercado são distorcidas, indo a favor das imensas corporações multinacionais e transnacionais que tomam posse, destroem ou incorporam as empresas pequenas e inovadoras que possam competir com as primeiras (assim denominado o estágio "câncer" do capitalismo). A política do mercado livre visa atender a demanda insaciável por mais lucros e não o bem comum dos sujeitos sociais. Tal política, comandada, em primeira linha, pelos Estados Unidos da América (EUA) e pela União Europeia, pretende mercantilizar a Educação, tratando as escolas nos moldes das grandes corporações, procurando administrar as instituições educativas a partir de interesses econômicos, havendo, assim, prevalência da lógica financeira sobre a lógica educacional.

É possível, portanto, perceber que a Educação começa a ser pensada e organizada como um bem a ser adquirido e não como um direito humano, passando a ser influenciada, de forma direta e direcionada pelos preceitos do mercado. A Educação, e o que se faz em seu nome, na atualidade, se tornou um excelente negócio. É possível perceber, ainda, nas novas orientações do sistema educacional, intensa ênfase ao individualismo e à competitividade, como se observa nas políticas públicas das avaliações externas, em que o Estado passa a 
ter um papel mais avaliador do que executor. Nas palavras de Peroni (2009, p. 49), o momento histórico atual pode ser compreendido como o tempo de "mercadificação de tudo": "[...] com os empresários definindo o conteúdo da gestão pública e os direitos sociais materializados em políticas universais transformados em políticas fragmentadas e focalizadas".

Em países que mercantilizaram a educação, as desigualdades sociais existentes aumentaram significativamente, e, do mesmo modo, o racismo, a violência, entre outros. Ainda no âmbito internacional, os mandamentos do Banco Mundial e do Fundo Monetário Internacional resultaram no desaparecimento dos serviços de saúde e educação gratuitos.

A partir das mudanças históricas e sociais ocorridas na sociedade atual, o conceito e a materialização da categoria trabalho vêm sofrendo modificações em relação ao que significavam no início do século passado, com repercussão em todos os âmbitos da vida humana e social. O conceito dessa categoria - que é central para os IFes, pois está relacionado diretamente às decisões e atuações em seu interior - no início do século XX era alçado como principal valor de uma sociedade, eixo seguro em torno do qual se fixavam autodefinições, identidades e projetos de vida. Na sociedade atual, a segurança proporcionada pelo mundo do trabalho é atingida muito mais pela precarização e flexibilização instalada nas relações entre patrões e empregados. As possibilidades de projetos de longa duração se fragilizam em situações nas quais não há garantia de que o emprego ou a empresa permanecerão por muito tempo em determinado local, por exemplo. A mentalidade de curto prazo acarreta implicações tanto nas relações interpessoais quanto na vida de trabalho das pessoas. "Escoltado pelo slogan 'flexibilidade' surge o advento do trabalho por contratos de curto prazo, ou sem contratos. 0 trabalho agora é um reino de incertezas" (BAUMAN, 2001, p. 169).

A partir disso, nos questionamos se este é o conceito de trabalho com o qual queremos pautar a Educação e a EF nos IFes. Ou seja, a educação técnica, tecnológica e centrada no mundo do trabalho seria incompatível com a Cultura Corporal do Movimento? Em caso afirmativo e conectado a esse entendimento (atrelado aos interesses do mercado de trabalho), há a possibilidade de a EF nos IFes seguir essa "onda"? Em nosso entendimento, a EF, na perspectiva de atender as demandas do mercado de trabalho, centra sua ação pedagógica na aquisição de capacidades físicas para o referido mercado. Nesse sentido, a EF pode ser "reconhecida" como um espaço de conscientização para a construção de estilos de vida saudáveis por parte dos potenciais trabalhadores. A reconfiguração no mundo do trabalho, abordada anteriormente, não demanda a formação de corpos fortes para as fábricas, mas, sim, indivíduos capazes de se readaptar às exigências de um mundo flexível e de uma sociedade em constante transformação. Em um mundo dominado pelas relações virtuais, o trabalho precisa, cada vez menos, estar "amarrado" ao corpo. Para Bauman (2001), o trabalho sem corpo da era do software não mais amarra o capital: permite ao capital ser extraterritorial, volátil e inconstante.

Os estilos de vida saudáveis, por sua vez, a serem ensinados na EF e cultivados individualmente não se destinam unicamente aos trabalhadores. Tais discursos se referem, com maior ênfase, às responsabilidades de cada um sobre seu corpo, para além da sua posição no mundo do trabalho, mas, ao mesmo tempo, para as possibilidades de vivenciar os prazeres oferecidos pela sociedade de consumo. Nessa direção, no emaranhado dos discursos que convivem em nossa área de conhecimento, o que prevalece é o cultivo de um corpo flexível, que se destina à responsabilidade (individual) de se ter um corpo saudável que não onere os cofres estatais, e, principalmente, a se ter um corpo atento e disponível para vivenciar as sensações contemporâneas. 
Nessa perspectiva, e de acordo com Gomes, Bracht e Almeida (2003), os docentes de $E F$, reconhecidos como profissionais dessa área, transformar-se-iam em conselheiros privados para a vida saudável e para um estilo de vida ativo. A partir disso, a EF (e seus profissionais) se restringiria a ser um dentre tantos conselheiros especializados no mercado dos estilos de vida, fornecendo dicas e mercadorias nas prateleiras identitárias contemporâneas para a melhora da qualidade de vida. Assim, os conselheiros da EF lutariam por fatias mercantis e seriam especialistas fundamentais na tarefa de disponibilizar informações e estratégias para os cuidados individuais com o corpo e, também, com a saúde. Sua tarefa escolar estaria entre o fomento da aptidão física e das responsabilidades individuais que o "amor de si" dessa época requer e os cuidados e aconselhamentos sobre a ansiedade que necessariamente estariam envolvidos nesse processo. Identificando-nos, nesse âmbito, ou não, essa é uma possibilidade que marca presença, atualmente, nas aulas de EF e nos estudantes que procuram um curso de Formação Inicial nessa área do conhecimento. Será essa a possibilidade da EF que queremos nos IFes?

Em contrapartida, considerando a pluralidade de horizontes possíveis em uma construção histórica, existem outras possibilidades para a EF, além da vinculada aos interesses mercantis, entre as quais as seguintes: aquela que, por acreditar em formação humana e cidadã, entende, entre outros elementos, que a categoria cidadão (categoria política) não pode ser substituída pela categoria consumidor (categoria econômica); a que compreende, pela mesma perspectiva, que precisamos lutar por direitos de cidadão e não por direitos de consumidor; a que compreende que a escola também é um lugar em que se ensina a lutar pela conquista e sustentação de direitos humanos e sociais, e não somente para que se tenha acesso ao "livre mercado", no qual tudo está à venda, incluindo a qualidade de vida, a saúde e a felicidade.

Por essa perspectiva, as possibilidades da EF nos IFes estariam relacionadas diretamente (no sentido de considerar) aos determinantes sociais e visariam a "crítica dos mecanismos e imposições resultantes da organização da sociedade em classes sociais antagônicas" (LIBÂNEO, 2012, p. 13). Isso implica, em nosso entendimento, entender que "o mundo que nos cerca não é, apenas, uma criação do espírito; ele existe concretamente. É dele, pois, que devemos partir para construir outra coisa, isto é, outro mundo" (SANTOS, 1998, p. 2).

Consideramos, portanto, que as manifestações da Cultura Corporal de Movimento, tratadas como conhecimentos na EF, no sentido exposto acima, seriam alvo de apropriação crítica e reflexiva por parte dos estudantes. Em uma perspectiva progressista, essas ideias estariam próximas do objetivo da EF Escolar traçado por Bracht e González (2005, p. 155): "objetiva-se, na Educação Física Escolar, assim, formar indivíduos dotados de capacidade crítica em condições de agir autonomamente na esfera da Cultura Corporal de Movimento e de forma transformadora como cidadãos políticos".

\section{CONSIDERAÇÕES TRANSITÓRIAS}

A capacidade crítica e a autonomia do estudante a serem desenvolvidas pela Educação Física nos IFes vão além do mero "exercitar-se", ou de fornecer "dicas" técnicas sobre como manter o corpo saudável, ou produtivo, ao gosto do mercado de trabalho, como se fôssemos exclusivamente profissionais da saúde e não docentes de EF. Um modo concreto de realizar esse intento é proporcionar aos estudantes, nas escolas, o acesso a conhecimentos que os auxiliem a compreender os determinantes objetivos envolvidos na disputa por modelos de 
práticas e de condutas corporais, por exemplo, aqueles que procuram reduzir o conceito de qualidade de vida às características subjetivas do "estilo de vida".

Essa é uma das maneiras possíveis que se distancia da prática de vender ilusões quanto ao corpo ou às práticas corporais; e se aproxima do entendimento de que está na conta da EF Escolar ajudar o estudante a compreender melhor o mundo em que vive, através de sua "janela" (a Cultura Corporal de Movimento), considerando, do mesmo modo, que os outros componentes curriculares compartilhem esse objetivo a partir de suas especificidades. $O$ conhecimento escolar em EF refere-se a esse elemento vivencial/discursivo referente às práticas corporais, o qual possibilita aos sujeitos compreenderem os modelos existentes na cultura de forma crítica, tendo opções para escolherem seus referenciais corporais com maiores condições de autonomia e de conscientização.

Destacamos, ainda, que esses argumentos podem se tornar secundários se, para a aula "da próxima segunda-feira pela manhã", o docente não tiver condições materiais objetivas para realizar seu trabalho. Não é gratuito que, dentre os fenômenos no âmbito da escola, dois tenham significativa importância para o professorado das escolas públicas. Segundo estudos do Grupo de Estudos Qualitativos Formação de Professores e Prática Pedagógica em Educação Física e Ciências do Esporte (F3P-EFICE) $)^{5}$ : 1) o primeiro trata do fenômeno da intensificação do trabalho docente; 2) e, o segundo, da crescente colonização do trabalho docente, por meio de "arrastões pedagógicos" e da oferta de Projetos Pedagógicos que desconsideram o tempo, o saber e a participação do professorado, levando os coletivos docentes a diferentes formas de pragmatismo pedagógico e, também, a manifestações dos processos de síndrome do esgotamento profissional (SANTINI; MOLINA NETO, 2005).

Lembramos que no campus do IFRS, no qual um de nós trabalha, não há quadra de esportes e, além disso, não há espaço específico para a EF. O docente deve "tirar um coelho da cartola"6 a cada aula. Esse exemplo pode ser considerado uma forma de desrespeito para com os estudantes, o docente e a área de conhecimento da EF. Em nossa análise, essa situação pode ser considerada nos resultados do embate histórico relacionado à legitimidade da EF na escola, que, infelizmente, estamos perdendo. É nessa perspectiva, por fim, que pensamos não ser possível refletir e considerar as possibilidades da EF Escolar sem relacioná-las ao que acontece social e politicamente na sociedade e na área da Educação. Nesse sentido, consideramos, também, as disputas por conceitos e por interpretações - que configuram a Educação em geral, e a Educação Técnica e Profissional em particular - com a própria questão da autoformação contínua do docente e com as pesquisas sobre a Educação e a EF Escolar. A obviedade da sentença acima também pode ser o motivo de sua invisibilidade, pois o fato é que ela não está sendo considerada nem discutida a contento: nem no contexto micro dos IFes nem na literatura da área da EF.

Compreendemos que um encaminhamento significativo para as reflexões aqui apresentadas possa ser: a criação de espaços para socializar experiências individuais e coletivas, registrando-as dos mais diversos modos e, necessariamente, submetendo-as à crítica dos nossos pares (colegas), sem a qual nossas "verdades" não passarão de "nossas próprias verdades", necessárias, porém não suficientes para enfrentar os significativos desafios atuais para a EF no Ensino Médio e Técnico.

5 Grupo de pesquisa registrado no Diretório de Grupos de Pesquisa do CNPq, vinculado institucionalmente à ESEF/UFRGS e coordenado pelo professor Vicente Molina Neto. Endereço eletrônico: http://www6.ufrgs.br/esef//3p-efice/index.htm. 
Para finalizar, chamamos a atenção para a relação entre educação, escola e sociedade. O que acontece e o que se faz no contexto escolar têm relação com a educação dos sujeitos e com a sociedade em que vivem, ou, como observa Morin (2009), com a construção de meios e de fazeres que permitam e contribuam para a formação e o desenvolvimento de um ser humano. Permitir, contribuir, colaborar, propor a formação e o desenvolvimento do sujeito é lidar com a vida humana, ou seja, com vidas que se entrecruzam em um momento histórico e em um contexto específico. Assim, educação, formação e desenvolvimento podem ser pensados a partir da construção de relações entre sujeitos que educam e são educados, transformam e são transformados, aprendem e ensinam em uma relação direta consigo mesmos, com os outros e com o mundo. Nesse sentido, Freire $(1982,1992,1996)$ se refere à educação como forma de os seres humanos partirem do que são para o que querem ser, e, através da "fé na capacidade das pessoas", construírem a história e se tornarem pessoas críticas na constituição de suas vidas e na transformação de suas realidades, a partir da relação eu-outro-mundo.

A escola - instituição pública, democrática, conquista política da cidadania e lugar de todos - pode ser assim compreendida: como um dos locais de realização da educação, formação e desenvolvimento das pessoas, através da participação, do exercício de voz, do diálogo, da tomada de decisões e das escolhas que acontecem nesse contexto, e, ao mesmo tempo, entendida como local de interpretação, de negociação, de manifestação, de construção de diversas culturas. A partir disso, a escola pode ser entendida como um espaço de construção de relações sociais e humanas, lugar para estudar, para se encontrar e se confrontar com os outros; dialogar, aprender, discutir, transformar; um espaço em que o sujeito vive e se torna humano.

\section{REFERÊNCIAS}

APPLE, Michael. Can education change society? New York: Routledge, 2013.

APPLE, Michael; AU, Wayne; GANDIN, Luís Armando. O mapeamento da educação crítica. In: APPLE, Michael; AU, Wayne; GANDIN, Luís Armando (Org.). Educação crítica: análise internacional. Porto Alegre: ARTMED, 2011. p.14-32.

BAUMAN, Zygmunt. Modernidade líquida. Rio de Janeiro: Jorge Zahar, 2001.

BRACHT, Valter; GONZÁLEZ, Fernando Jaime. Educação física escolar. In: GONZÁLEZ, Fernando Jaime; FENSTERSEIFER, Paulo Evaldo (Org.). Dicionário crítico de educação física. ljuí: Unijuí, 2005. p. 150-157.

BRASIL. Lei no 11.195 de 18 de novembro de 2005. Dá nova redação ao $\S 5^{\circ}$ do art. $3^{\circ}$ da Lei nº 8.948, de 8 de dezembro de 1994. Disponível em: <http://www.planalto.gov.br/ccivil 03/ Ato20042006/2005/Lei/L11195.htm>. Acesso em: 1‥ dez. 2014.

BRASIL. Lei no 11.892 de 29 de dezembro de 2008. Institui a Rede Federal de Educação Profissional, Científica e Tecnológica, cria os Institutos Federais de Educação, Ciência e Tecnologia, e dá outras providências. Brasília, 29 dez. 2008. Disponível em: <http://www.planalto.gov.br/ccivil_03/ ato2007-2010/2008/lei//11892.htm>. Acesso em: 18 nov. 2014.

BRASIL. Resolução no 2, de 30 de janeiro de 2012. Define Diretrizes Curriculares Nacionais para o Ensino Médio. Disponível em: <http://pactoensinomedio.mec.gov.br/images/pdf/resolucao ceb 002 30012012.pdf>. Acesso em: 1‥ dez. 2014. 
CARVALHO, Olgamir F.; LACERDA, Gilberto. Dualismo versus congruência: diálogo entre o novo método brasileiro para a formação profissional e o modelo didático ESC (Experiencial, Científico e Construtivista). In: MOLL, Jaqueline (Org.). Educação profissional e tecnológica no Brasil contemporâneo: desafios, tensões e possibilidades. Porto Alegre: Artmed, 2010. p. 301-312.

CONTRERAS DOMINGO, José. La autonomia del profesorado. Madrid: Morata, 1997.

FENSTERSEIFER, Paulo Evaldo. Conhecimento, epistemologia e intervenção. In: GOELLNER, Silvana Vilodre. Educação Física/Ciências do Esporte: intervenção e conhecimento. Florianópolis: Colégio Brasileiro de Ciências do Esporte, 1999. p. 171-183.

FREIRE, Paulo. Pedagogia do oprimido. 11. ed. Rio de Janeiro: Paz e Terra, 1982.

FREIRE, Paulo. Pedagogia da esperança: um reencontro com a Pedagogia do oprimido. 12. ed. Rio de Janeiro: Paz e Terra, 1992.

FREIRE, Paulo. Pedagogia da autonomia: saberes necessários à prática educativa. São Paulo: Paz e Terra, 1996.

GOMES, Ivan Marcelo; BRACHT, Valter; ALMEIDA, Felipe Quintão. Do corpo produtivo ao corpo consumidor: a Educação Física na modernidade líquida. In: CONGRESSO ARGENTINO Y LATINOAMERICANO DE EDUCACIÓN FÍSICA Y CIENCIAS, 2013, La Plata. Anais.... p. 1-8. Disponível em: <http://congresoeducacionfisica.fahce.unlp.edu.ar/10o-ca-y-50-l-efyc/actas-10-y-5/ Eje4 Mesa C Almeida.pdf>. Acesso em: 1ํ. dez. 2014.

HILL, Dave. Neoliberalismo Global, a Resistência e a Deformação da Educação. Revista Currículo Sem Fronteiras, Porto Alegre, v. 3, n. 2, p. 24-59, jul./dez. 2003.

MARCONDES, Danilo. Textos básicos de filosofia: dos pré-socráticos a Wittgenstein. 6 . ed. Rio de Janeiro: Zahar, 2009.

LIBÂNEO, José Carlos. Democratização da escola pública: a pedagogia crítico-social dos conteúdos. 27. ed. São Paulo: Loyola, 2012.

MORIN, Edgar. A cabeça bem-feita: repensar a reforma, reformar o pensamento. 16. ed. Rio de Janeiro: Bertrand Brasil, 2009.

PACHECO, Eliezer. Os institutos federais: uma revolução na educação profissional e tecnológica.

MEC. Disponível em: <http://portal.mec.gov.br/index.php?id=14428\&option=com content\&view=article>. Acesso em: 30 jul. 2012.

PERONI, Vera Maria Vidal. As políticas educacionais em tempos de mercadificação de tudo. In: TRIVIÑOS, Augusto Silva Nibaldo; BÚRIGO, Carla Cristina Dutra; OYARZABAL, Graziela Macuglia. A formação de professores para educação básica na América Latina: problemas e possibilidades. Florianópolis: Imprensa Universitária/UFSC, 2009. p. 39-50.

REIS, José Antônio Padilha dos; MOLINA NETO, Vicente. "Pensei que tava na aula de ciências" ou os significados da educação física na educação de jovens e adultos. Pensar a Prática, Goiânia, v. 17, n. 3, p. 636-650, jul./set. 2014.

SANTINI, Joarez; MOLINA NETO, Vicente. A síndrome do esgotamento profissional em professores de educação física: um estudo na rede municipal de ensino de Porto Alegre. Revista Brasileira de Educação Física e Esportes, São Paulo, v. 19, n. 3, p. 209-22, jul./set. 2005.

SANTOS, Milton. 0 professor como intelectual na sociedade contemporânea. Disponível em: $<$ http://extensao.fecap.br/artigoteca/Art 016.pdf>. Acesso em: 20 nov. 2014.

SILVA, Eduardo Marczwski da. A Educação Física no currículo de Escolas Profissionalizantes da Rede Federal: uma espécie em processo de mutação. 2014, 147 folhas. Tese (Doutorado em Ciências do Movimento Humano) - Escola de Educação Física, Universidade Federal do Rio Grande do Sul, Porto Alegre, 2014. 